\title{
Physical Simulation on Molten Steel Flow Characteristics of RH Vacuum Chamber with Arched Snorkels
}

\author{
Zhi-Feng Ren $\mathbb{D}^{1,2,3}$ Zhi-Guo Luo ${ }^{1,},{ }^{1}$ Fan-Xia Meng $\left(\mathbb{D},{ }^{4}\right.$ Zong-Shu Zou, ${ }^{1}$ Yi-Hong Li, ${ }^{2,3}$ \\ Ai-Chun Zhao $\mathbb{D}^{2,3}$ and Hai-Lian Gui ${ }^{2,3}$ \\ ${ }^{1}$ School of Metallurgy, Northeastern University, Shenyang 110819, China \\ ${ }^{2}$ School of Materials Science and Engineering, Taiyuan University of Science and Technology, Taiyuan 030024, China \\ ${ }^{3}$ Engineering Research Center Heavy Machinery Ministry of Education, Taiyuan University of Science and Technology, \\ Taiyuan 030024, China \\ ${ }^{4}$ State Key Laboratory of Rolling and Automation, Northeastern University, Shenyang 110819, China
}

Correspondence should be addressed to Zhi-Guo Luo; luozg@mail.neu.edu.cn and Fan-Xia Meng; 1610196@stu.neu.edu.cn

Received 11 May 2020; Revised 30 July 2020; Accepted 10 August 2020; Published 30 August 2020

Academic Editor: Jan Koci

Copyright ( 2020 Zhi-Feng Ren et al. This is an open access article distributed under the Creative Commons Attribution License, which permits unrestricted use, distribution, and reproduction in any medium, provided the original work is properly cited.

\begin{abstract}
The RH vacuum refining technology is a vitally powerful method of producing clean steel. The inner diameter of traditional circular snorkel is very difficult to be increased owing to the metallurgical refractory thickness around the snorkels and the limitation of the area under the vacuum chamber, limiting the increase in refining efficiency. In order to improve the refining efficiency of the RH reactor, a new designed RH degasser with an optimized arched snorkel is established. This design replaces the traditional two circular snorkels structure with the two arched snorkels and greatly enhances the cross-sectional area of snorkel. In this study, the flow characteristics of this new type RH were studied and analyzed by establishing a 1:5.5 physical model of RH with arched snorkels. Results show that the circulation flow rate of RH with arched snorkels can increase by $100 \% \sim 180 \%$ and the mixing time approximately decreases by $35 \%$ compared with $\mathrm{RH}$ with circular snorkels under actual production conditions. The circulation flow rate of $\mathrm{RH}$ with arched snorkels continues to increase obviously when gas flow rate exceeds the saturated value of $\mathrm{RH}$ with circular snorkels. The RH with arched snorkels can increase the refining efficiency significantly and has important application prospect.
\end{abstract}

\section{Introduction}

As a tool for molten steel secondary refining, the Ruhrstahl-Heraeus $(\mathrm{RH})$ processing has wide applications owing to its multiple metallurgical functions, such vacuum degassing, decarburization, inclusion removal, denitrogenation, and inclusion removal. It is widely used for the production of ultralow carbon steels, bearing steels, pipeline steels, spring steels, silicon steels, etc. The RH vacuum steel degassing process depends on sucking the liquid steel from the ladle to the vacuum chamber equipped with two snorkels (up-leg and down-leg) [1]. When the inert gas is blown to the liquid steel, then the circulation flow of steel between vacuum chamber and ladle is forced. The degassing process mainly occurs in liquid internal [1], at splashed metals in vacuum chamber and bubble surfaces $[2,3]$, which involves complex chemical reactions and transport phenomena [4]. Thus, to improve the degassing and decarburization rate and promote the inclusion removal rate in the RH systems, it is important to illustrate liquid steel flow characteristics. Nevertheless, the RH system can hardly be observed directly because of its complex physical and pyrometallurgical process, which involves thermodynamics, kinetics, and multiphase flow and mass transfer [4]. The problem was suddenly thrown into sharp focus. In order to reduce costs, many researchers are very concerned about improving the refining efficiency of $\mathrm{RH}$ equipment. It is generally considered that the circulation flow rate [5-10] and the mixing time [11-16] are two significant parameters during the $\mathrm{RH}$ process. Thus, many researchers have developed physical $[10,11,17-21]$ or mathematical models $[5,13,22-27]$ to simulate the multiphase flow $[13,22,26-29]$, mixing 
phenomena [10-16, 28-31], behavior of bubble and inclusion removal [22, 30, 32], and decarburization process $[1,2,8,20,23,25,33,34]$ during the $\mathrm{RH}$ treatment. Based on the physical simulation experiment work of predecessors on circulation flow rate of $\mathrm{RH}$, some empirical formulas are listed in Table 1, which includes the formulas put forward at the first time and excludes similar equations reported later. It is generally accepted that the circulation flow rate of $\mathrm{RH}$ is related to the injected gas flow rate and the section size of snorkel. From process parameter improvement view, many researches have proved that a higher gas flow rate $[5,7,29,30,34]$, a lower vacuum pressure $[18,19,28]$, a deeper insertion depth of snorkel $[3,14]$ would favor to optimize the fluid flow of RH. However, the circulation rate will reach a saturated value with the gas flow rate increasing $[14,36]$. From equipment improvement view, many investigations have proved that a larger snorkel sectional area $[24,26,29,38]$ blowing from the bottom of the vacuum chamber [15] or ladle [39] would favor to optimize the fluid flow of RH. Recently, many researchers have tried to increase the refining efficiency by using single-leg $[12,28,31,40]$, multilegs [38, 41], and magnetic field [42] imposed around the up-leg. However, the single-leg was hardly used in the actual industrial manufacture considering technical immaturity; meanwhile, multilegs and imposing magnetic field around snorkel were also hardly used in the actual industrial manufacture considering the cost issue. All of the equations in Table 1 imply that the arched snorkels with greater sectional area would bring a larger circulation flow rate. Additionally, the stimulus-response was the general method used to measure the mixing time $[7,10]$, another important parameter for the RH treatment. In the physical simulation experiments of this paper, this method will continue to observe the mixing of molten steel.

However, little results $[38,42]$ were reported to study the shape of RH snorkels, which has always been circular until the oval snorkel was proposed by Kuwabara [15]. The oval snorkels were favored to enhance fluid flow of $\mathrm{RH}$, but we want the refining efficiency to keep getting bigger, including a great increase in circulation flow rate and saturated value of gas flow rate. In the current study, a new vacuum degasser equipped with two snorkels of larger sectional area was designed. The two traditional circular snorkels were replaced with two arched snorkels, which was not reported in previous investigations. For the arched snorkel, the internal arc height is equal to the radius of traditional circular snorkel and the internal diameter is 3 to 4 times of the circular snorkel. Hence, the sectional area of arched snorkel is much larger than that of circular snorkel. Water modeling was performed according to similarity criterion. The flow velocity of the $\mathrm{RH}$ water model down-on leg-outlet plane was captured by electronic tachometer, and the stimulus-response method was used to measure the mixing time. The results provided the experimental basis for promoting and improving this new $\mathrm{RH}$ vacuum refining equipment.

\section{Experiment}

2.1. Model Design. The prototype is one $\mathrm{RH}$ vacuum chamber with two circular snorkels from a steel plant in
China. According to the empirical formulas listed in Table 1, we have determined the kernel idea of this design is to increase the cross-sectional area of snorkel as much as possible. The scale of water model and prototype is $1: 5.5$. Figure 1(a) shows the model size of circular snorkel. The circular snorkel diameter is very difficult to be increased owing to the metallurgical refractory thickness around the snorkels and the limitation of the area under the vacuum chamber. In order to increase the cross-sectional area of the snorkel as much as possible, two snorkels are changed to arched structures in this research. So as to make full use of the space under the vacuum chamber, the inner diameter of the vacuum chamber is determined as the diameter of arched snorkel and the arc height is same as the inner diameter of circular snorkel, utilizing the bottom space of the vacuum chamber optimized. Figure 1(b) exhibits the top view of the arched snorkel water model. Compared with circular snorkel, this arched structure increases the equivalent inner diameter by approximately $70 \%$ and the cross-sectional area by $193 \%$ in this design.

2.2. Similarity Theory. A $1: 5.5$ scale water model of $170 t \mathrm{RH}$ was built according to the similarity principle. Table 2 shows the main parameters of the prototype and physical model. The lifting gas flow rate of model $Q_{m}$ is calculated from the actual gas flow rate on-site $Q_{p}$ with the modified Froude criterion according to the following equation:

$$
Q_{m}=0.01448 Q_{p}
$$

2.3. Experimental Device and Parameters. The water model experimental devices consist of vacuum chamber and ladle made of plexiglass. Two snorkels are equipped at the bottom of the vacuum chamber. To the $\mathrm{RH}$ with two circular snorkels, compressed air is used as the lifting gas through six evenly distributed gas injection nozzles in one horizontal plane of circular up-leg. To the RH with two arched snorkels, four nozzles are distributed evenly in the arc of the arched up-leg, two others are distributed evenly in the chord, and these six nozzles are in one horizontal plane of arched upleg. This model also includes the gas source system, gas distributor and transmission pipeline, vacuuming system, metering system, and detection system. Figure 2 shows the schematic of the main apparatus of the water model.

The gas flow rate is $60 \sim 130 \mathrm{Nm}^{3} \cdot \mathrm{h}^{-1}$, the pressure in the vacuum chamber is $67 \mathrm{~Pa}$, and insertion depth of snorkel is $627 \mathrm{~mm}$ in the production site. Table 3 shows the corresponding parameters of the prototype and water model.

\subsection{Experimental Index}

2.4.1. Circulation Flow Rate. The circulation flow rate $G_{m}$ was obtained by measuring the fluid velocity, which was $20 \mathrm{~mm}$ above the outlet of the down-leg. Five measuring points were horizontally and longitudinally set at the crosssectional center of down-leg. The fluid velocity at the measuring point was obtained with an electronic tachometer 
TABLE 1: Equations for circulation flow rate.

\begin{tabular}{|c|c|c|c|}
\hline Author & Equations & Variables & Reference \\
\hline $\begin{array}{l}\text { Watanabe } \\
\text { et al. }\end{array}$ & $Q=0.020 D^{1.5} G^{0.33}$ & $\begin{array}{c}\text { Q: circulation flow rate, } t \cdot \mathrm{min}^{-1} ; \\
G \text { : gas flow rate, NL·min }{ }^{-1} ; D \text { : diameter of snorkel, } \mathrm{m}\end{array}$ & {$[35]$} \\
\hline Tokio et al. & $Q=K \cdot D^{1.5} G^{0.33}$ & $K:$ constant & [11] \\
\hline $\begin{array}{l}\text { Seshadri and } \\
\text { Costa }\end{array}$ & $Q=\rho \cdot S \cdot\left(0.74 G \ln \left(P_{2} / P_{1}\right)\right)^{1 / 3}$ & $\begin{array}{c}\rho: \text { liquid density, } \mathrm{g} \cdot \mathrm{cm}^{-3} ; S: \text { section area of snorkel, } \mathrm{m}^{2} \\
P_{1}: \text { pressure at top level, } \mathrm{Pa} ; P_{2}: \text { pressure at injection point, } \mathrm{Pa}\end{array}$ & {$[36]$} \\
\hline $\begin{array}{l}\text { Kuwabara } \\
\text { et al. }\end{array}$ & $Q=K \cdot G^{1 / 3} D^{4 / 3}\left[\ln P_{1} / P_{2}\right]^{4 / 3}$ & $\begin{array}{l}P_{1}: \text { pressure at blowing point, atm } \\
P_{2}: \text { pressure at vacuum vessel, atm }\end{array}$ & [15] \\
\hline Kamata et al. & $Q=11.4 Q_{g}^{(1 / 3)} d_{p}^{(4 / 3)}\left(\ln 1+\rho_{1} g h / P_{v}\right)^{(1 / 3)}$ & $\begin{array}{l}Q_{\mathrm{g}} \text { : gas flow rate, NL·min }{ }^{-1} ; d_{\mathrm{p}} \text { : diameter of snorkel, } m ; \rho_{\mathrm{l}} \text { : liquid } \\
\text { density, } \mathrm{g} \cdot \mathrm{cm}^{3} ; g \text { : gravitational acceleration, } \mathrm{m} \cdot \mathrm{s}^{-2} ; h \text { : gas inject } \\
\text { depth, } \mathrm{cm} ; P_{\mathrm{V}} \text { : vacuum chamber pressure, } \mathrm{Pa}\end{array}$ & {$[37]$} \\
\hline
\end{tabular}

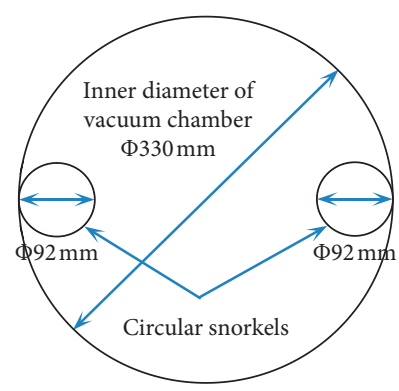

(a)

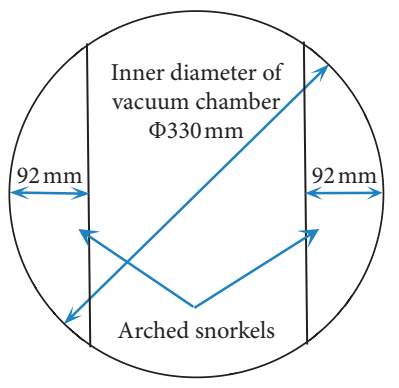

(b)

FIgURE 1: Model schematic of the RH vacuum chamber with (a) circular and (b) arched snorkels (top view).

TABLe 2: Parameters of the prototype and water model.

\begin{tabular}{lccc}
\hline Item & $\begin{array}{c}\text { Prototype } \\
(\mathrm{mm})\end{array}$ & $\begin{array}{c}\text { Water model for circular snorkels } \\
(\mathrm{mm})\end{array}$ & $\begin{array}{c}\text { Water model for arched snorkels } \\
(\mathrm{mm})\end{array}$ \\
\hline Diameter of ladle top & 3077 & 564 & 564 \\
Diameter of ladle bottom & 2666 & 489 & 489 \\
Height of ladle & 3806 & 692 & 692 \\
Inner diameter of vacuum chamber & 1800 & 330 & 330 \\
Height of vacuum chamber & 10350 & 1000 & 1000 \\
Internal diameter of circular snorkel & 500 & 92 & 92 \\
Internal diameter of arched snorkel & 1800 & 330 & 330 \\
Internal arc height of arched snorkel & 500 & 275 & 92 \\
Length of snorkels & 1500 & 1.1 & 275 \\
Inner diameter of gas injection nozzles & 6 & 100 & 1.1 \\
Distance between nozzles and bottom of vacuum & 550 & 100 \\
chamber & & & 1 \\
\hline
\end{tabular}

(XC-LSB-1, XINGLIANCHEN Technology Co., Ltd., China). Each measurement was repeated three times, and the cross-sectional velocity was obtained by the average value of all measuring points. The circulation flow rate was the product of the measured velocity and cross-sectional area of the down-leg.

2.4.2. Mixing Time. The mixing time $T_{\text {mix }}$ was measured by an electrical conductivity meter $[18,36]$. The saturated $\mathrm{NaCl}$ aqueous solution was used as the tracer. When the fluid flow in the model was stable, the saturated $\mathrm{NaCl}$ aqueous solution was injected into the water through the spare nozzle on top of up-leg. Meanwhile, the conductivity instrument (DDS307A, INESA Scientific Instrument Co., Ltd., China) was employed to measure the conductivity until a stable value $\left(C_{\infty}\right)$ was reached. The time for reaching the stable value is called mixing time. The conductivity probe was placed $60 \mathrm{~mm}$ below the ladle liquid level in the center between the up-leg and down-leg.

2.5. RH Work Principle and Bubble Behavior. The lifting gas is injected into the molten steel through the nozzles, and discrete spherical bubbles are formed at the nozzle exit. The bubbles with initial horizontal velocity enter into up-leg from the nozzles, and then the bubbles float upward and drive the molten steel up. Figure 3 shows the schematic of the bubble formation and motion path. 


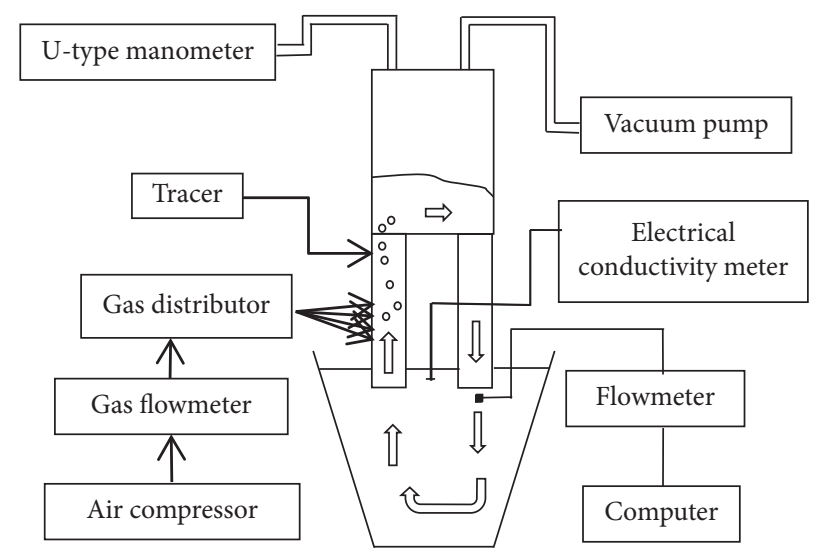

FIGURE 2: Schematic of water modeling.

TABLE 3: Parameters of the prototype and water model.

\begin{tabular}{|c|c|c|c|c|c|c|c|c|c|c|c|}
\hline Main parameters & Vacuum degree $(\mathrm{Pa})$ & \multicolumn{6}{|c|}{ Gas flow rate $\left(\mathrm{Nm}^{3} \cdot \mathrm{h}^{-1}\right)$} & \multicolumn{4}{|c|}{ Insertion depth of snorkel (mm) } \\
\hline Prototype & 67 & 35 & 69 & 104 & 138 & 173 & 193 & 382 & 545 & 710 & 818 \\
\hline Model & 97709 & 0.5 & 1 & 1.5 & 2 & 2.5 & 2.8 & 70 & 100 & 130 & 150 \\
\hline
\end{tabular}

The molten steel circulation process between the vacuum chamber and the ladle in RH vacuum degasser is similar to the "bubble pump" mechanism. A certain height difference between the liquid levels in the vacuum chamber and ladle is created in the vacuum degree of the vacuum chamber. The lifting gas first enters into molten steel in the form of bubbles, floats upward, and then expands with the temperature increase and pressure decrease. Accordingly, the density of gas-liquid two-phase in the up-leg reduces. The molten steel in the ladle is driven to the up-leg and then flows out through the down-leg due to gravity after entering the vacuum chamber. Thereafter, a circulation flow is formed, and the following equation is achieved [8, 14, 17]:

$$
A_{\text {gas }}=A_{\text {steel }}+A_{\text {loss }} \text {, }
$$

where $A_{\text {gas }}$ is the gas expansion work, $J$; $A_{\text {steel }}$ is the work for lifting molten steel, $J$; and $A_{\text {loss }}$ is the lost work, $J$.

Considering $A_{\text {loss }}$ is small, equation (2) can be expressed as

$$
A_{\text {gas }}=A_{\text {steel }}=M H g=M\left(\frac{P_{0}-P}{\rho_{g-1}} \frac{P_{0}-P}{\rho_{1}}\right)
$$

where $M$ is the quality of lifting liquid steel, $\mathrm{kg} ; H$ is the lifting height of liquid steel, $m ; P_{0}$ is the atmospheric pressure, $\mathrm{Pa} ; \mathrm{g}$ is the acceleration of gravity, $\mathrm{m} \cdot \mathrm{s}^{-2} ; P$ is vacuum chamber pressure, $\mathrm{Pa} ; \rho_{\mathrm{g}-1}$ is the density of gas-liquid two-phase, $\mathrm{kg} \cdot \mathrm{m}^{-3}$; and $\rho_{1}$ is the density of liquid, $\mathrm{kg} \cdot \mathrm{m}^{-3}$. The density of the gas-liquid two-phase is the weighted value of the gas and liquid phases and obtained from equation (4) [17] as follows:

$$
\rho_{g-1}=\alpha \cdot \rho_{g}+(1-\alpha) \cdot \rho_{1},
$$

where $\alpha$ is the gas holdup.

\section{Results and Discussion}

\subsection{Comparison of RH with Circular Snorkels and RH with Arched Snorkels}

3.1.1. Flow Field. Under the condition of vacuum chamber pressure $(P=97709 \mathrm{~Pa})$, insertion depth of snorkel $\left(H_{\mathrm{imm}}=100 \mathrm{~mm}\right)$, gas flow rate $\left(Q_{\mathrm{m}}=1.0 \mathrm{Nm}^{3} \cdot \mathrm{h}^{-1}\right)$, and flow field using the black ink as tracer is shown in Figure 4. The ink was injected into up-leg through the spare nozzle on the top of up-leg. A high-speed camera was used to record the flow field. As shown in the flow fields from the water models, the molten steel driven by lifting gas flowed into the vacuum chamber through the up-leg, and violent mixing occurred in the vacuum chamber. Then, the molten steel flowed downward the ladle through down-leg, reached the ladle bottom, and rose upward again. The time of tracer in $\mathrm{RH}$ with arched snorkels to complete the mixing in the vacuum chamber, reaching the ladle bottom and complete one cycle, was, respectively, $3 \mathrm{~s}, 12 \mathrm{~s}$, and $18 \mathrm{~s}$ and that of $\mathrm{RH}$ with circular snorkels was $3 \mathrm{~s}, 18 \mathrm{~s}$, and $44 \mathrm{~s}$. Compared with $\mathrm{RH}$ with circular snorkels, the quantity of the flowing molten steel through down-leg increases with the increase of the cross-sectional area and has a better diffusion capacity in the ladle while flowing to the bottom of the ladle in $\mathrm{RH}$ with arched snorkels. The mixing capacity of RH with arched snorkels was stronger than that of RH with circular snorkels.

3.1.2. Saturated Gas Flow Rate. In water model experiment, the circulation flow rate increases with the gas flow rate. After reaching a certain value, the circulation flow rate tends to be saturated. The circulation flow rate at this time is called saturated circulation flow rate $G_{m \text {, max }}$, and the minimum gas flow rate corresponding to the $G_{m \text {, max }}$ is called saturated gas flow rate $Q_{m, \max }[14,36]$.

The horizontal section and horizontal trajectory of the bubbles in gas-liquid plume observed schematically at the 


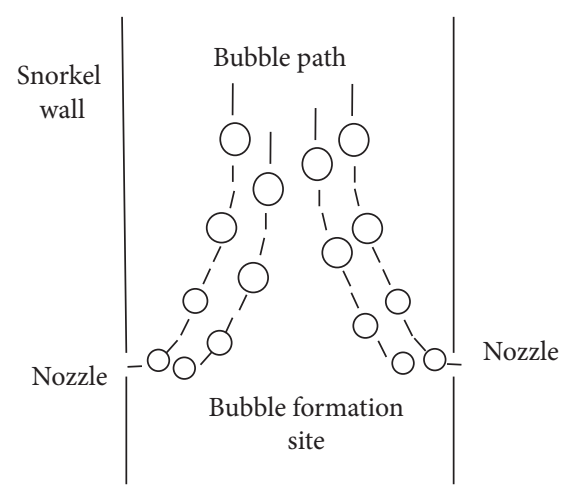

FIgURE 3: Schematic of the formation and path of bubbles in up-leg.

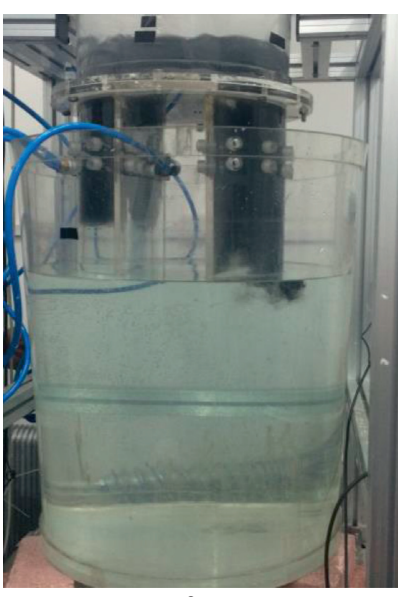

$3 s$

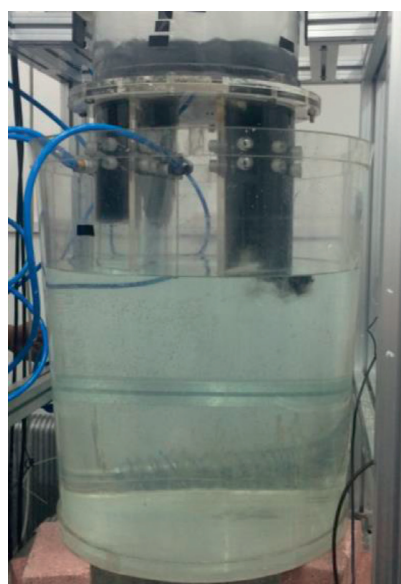

$3 \mathrm{~s}$

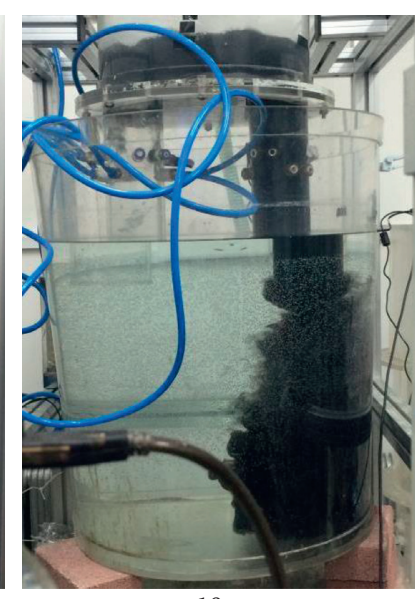

(a)

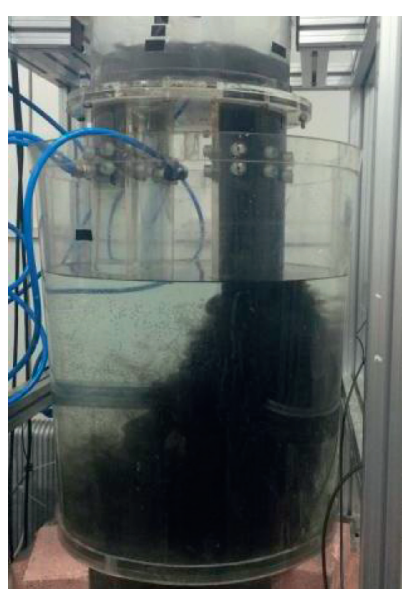

$12 \mathrm{~s}$

(b)
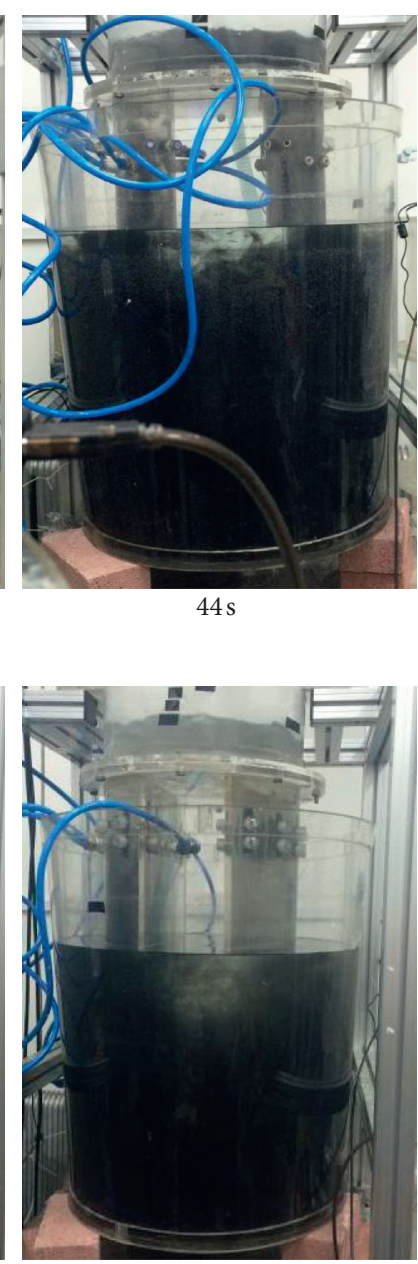

$18 \mathrm{~s}$

FIgURe 4: Flow field of (a) RH with circular snorkels and (a) RH with arched snorkels in one circulation.

outlet of the up-leg are shown schematically in Figure 5. For the two RH models, the bubbles in the gas-liquid plume formed at the exit of each nozzle are individually close to the wall of up-leg at small gas flow rate. With the increase of the gas flow rate, the diameter and horizontal penetrating depth of bubbles in gas-liquid plume increase. When the gas flow rate tends to be $Q_{m}$, max , the bubbles in gas-liquid plume will collide with each other for RH with circular snorkels as shown in Figure 5(a), and bubbles from nozzle 2 and 3 will collide the opposite wall lastly for RH with arched snorkels as shown in Figure 5(b). If the gas flow rate continues to increase and the bubbles are in the state of ejection, the gas driving power will be greatly reduced and the circulation flow rate will tend to be saturated. Therefore, it can be 
considered that the gas flow rate corresponding to the contact of bubbles from different nozzles with each other or the contact of bubbles and opposite wall is $Q_{m}$ max. The bubble is simulated by a complete sphere, and the geometric conditions of this contact state of $\mathrm{RH}$ with circular snorkels and RH with arched snorkels are expressed by equations (5) and (6) [10]. Equations (7)-(9) [37] show the calculation formulas of diameter and horizontal penetrating depth of bubble; by combining equations (5) and (6), the $Q_{m}$ max of the two RH water models can be calculated:

$$
d_{B}=\left(\frac{d_{p}}{2-L_{B}}+\frac{d_{B}}{2}\right) * 2 \sin \left(\frac{\theta_{N}}{2}\right),
$$

$$
\frac{d_{p} / 2-H_{s}}{\cos \left(\theta_{N} / 2\right)}+L_{B}=\frac{d_{p}}{2},
$$

where $d_{B}$ is the bubble diameter, $m$; $d_{p}$ is the diameter of up-leg, $m ; L_{B}$ is the horizontal penetrating depth of bubble, $m ; H_{s}$ is internal arc height; and $\theta_{N}$ is the angle between adjacent nozzles; for circular snorkel, $\theta_{N}=2 \pi / n_{c}$ ( $n_{c}$ is the nozzle number); for arched snorkel, $\theta_{N}=\arccos \left[\left(0.5 d_{p}-H_{s}\right) / 0.5 d_{p}\right] / 2.5$ :

$$
\begin{aligned}
& d_{B}=\left[\left(\frac{6 \sigma d_{0}}{\rho_{1} g}\right)^{2}+\left\{0.54\left[\frac{Q_{g}}{4 n} d_{0}^{0.5}\right]^{0.289}\right\}^{6}\right]^{1 / 6}, \\
& \frac{L_{B}}{d_{0}}=3.7\left[\frac{\rho_{g}}{\rho_{1}-\rho_{g}} \frac{V_{g}^{2}}{g d_{0}}\right]^{1 / 3}, \\
& V_{g}=\frac{Q_{g} / n}{\pi d_{0}^{2} / 4},
\end{aligned}
$$

where $d_{0}$ is the nozzle diameter, $m$; $\sigma$ is the surface tension in the liquid phase, $\mathrm{N} \cdot \mathrm{m}^{-1} ; \rho_{1}$ and $\rho_{g}$ are the density of liquid and phase, $\mathrm{kg} \cdot \mathrm{m}^{-3} ; n$ is the nozzle number; $V_{g}$ is the orifice gas velocity, $\mathrm{m} \cdot \mathrm{s}^{-1} ; \mathrm{g}$ is the acceleration of gravity, $\mathrm{m} \cdot \mathrm{s}^{-2}$; and $Q_{g}$ is the gas flow rate, $\mathrm{Nm}^{3} \cdot \mathrm{s}^{-1}$.

The $Q_{m \text {,max }}$ of $\mathrm{RH}$ with circular snorkels calculated from above is $2.52 \mathrm{Nm}^{3} \cdot \mathrm{h}^{-1}$. And, this is $5.03 \mathrm{Nm}^{3} \cdot \mathrm{h}^{-1}$ to $\mathrm{RH}$ with arched snorkels. The $Q_{m \text { max }}$ of $\mathrm{RH}$ with arched snorkels is approximately $99.6 \%$ higher than that of the $\mathrm{RH}$ with circular snorkels from theoretical calculations.

Figure 6(a) shows the variation of circulation flow rate $G_{m}$ and gas flow rate $Q_{m}$ under the conditions that insertion depth of snorkel $H_{\mathrm{imm}}$ is $70,100,130$, and $150 \mathrm{~mm}$, respectively. The $G_{m}$ increased with the increase of $H_{\mathrm{imm}}$, and the $G_{m}$ of RH with circular snorkels showed saturation tendency at about 2.50 $\mathrm{Nm}^{3} \cdot \mathrm{h}^{-1}$ of $Q_{m}$ even at different $H_{\mathrm{imm}}$, which was very consistent with the calculated value $\left(2.52 \mathrm{Nm}^{3} \cdot \mathrm{h}^{-1}\right)$. The $Q_{m \text {, max }}$ is the result of the horizontal movement of the bubbles and is independent of the insertion depth of snorkel. Therefore, Figure 6(b) only shows the variation of the $G_{m}$ and $Q_{m}$ under the condition of $H_{\mathrm{imm}} 70 \mathrm{~mm}$; the $G_{m}$ kept increasing with the increase of $Q_{m}$, because the $Q_{\mathrm{m} \text {,max }}$ of $\mathrm{RH}$ with arched snorkels was $5.03 \mathrm{Nm}^{3} \cdot \mathrm{h}^{-1}$.
According to equation (1), the $Q_{p \text {,max }}$ of $\mathrm{RH}$ with arched snorkels is $347 \mathrm{Nm}^{3} \cdot \mathrm{h}^{-1}$ on-site, which is far beyond the gas flow rate $\left(60 \sim 130 \mathrm{Nm}^{3} \cdot \mathrm{h}^{-1}\right)$ in the production site. Excessive gas flow rate will result in mismatching of vacuum pump and other equipment. Therefore, it is not necessary to extend the gas flow rate to its $Q_{m \text {,max }}$ of $\mathrm{RH}$ with arched snorkels in this physical simulation.

3.1.3. Circulation Flow Rate and Mixing Time. Under the condition of vacuum chamber pressure $(P=97709 \mathrm{~Pa})$ and insertion depth of snorkel $\left(H_{\mathrm{imm}}=100 \mathrm{~mm}\right)$, the relationship between the circulation flow rate $G_{m}$ and gas flow rate $Q_{m}$ in $\mathrm{RH}$ with arched snorkels and $\mathrm{RH}$ with circular snorkels is compared in Figure 7. It can be seen that the $G_{m}$ of RH with arched snorkels was much larger than that of $\mathrm{RH}$ with circular snorkels in the whole $Q_{m}$. Under the same experimental conditions, the $G_{m}$ of $\mathrm{RH}$ with arched snorkels was $2.0 \sim 2.8$ times that of $\mathrm{RH}$ with circular snorkels. This result indicated that the $G_{m}$ increases with the cross-sectional area increase of the arched snorkel; such result verified the previous studies that the circulation flow rate increases with the increase of cross-sectional area of the snorkel $[3,24,38]$.

Under the condition of $P=97709 \mathrm{~Pa}$ and $H_{\mathrm{imm}}=100 \mathrm{~mm}$, the relationship between mixing time $T_{\text {mix }}$ and $Q_{m}$ in $\mathrm{RH}$ with arched snorkels and $\mathrm{RH}$ with circular snorkels is compared in Figure 8. It can be seen that the $T_{\text {mix }}$ decreased with the increase in $Q_{m}$. When the $Q_{m}$ was $2.0 \mathrm{Nm}^{3} \cdot \mathrm{h}^{-1}$, the $T_{\text {mix }}$ of $\mathrm{RH}$ with arched snorkels was $74 \mathrm{~s}$, whereas that of $\mathrm{RH}$ with circular snorkels was $118 \mathrm{~s}$. Under the experimental condition, the $T_{\text {mix }}$ of $\mathrm{RH}$ with arched snorkels was $63 \% \sim 70 \%$ that of $\mathrm{RH}$ with circular snorkels.

3.2. Effect of Gas Flow Rate and Insertion Depth of Snorkel on $R H$ with Arched Snorkels. The $G_{m}$ increases with the increase of $Q_{m}$ and $H_{\text {imm. }}$. Equations (7)-(9) demonstrate that the bubble number, diameter, and horizontal penetrating depth increase with the increase in $Q_{m}$, the work conducted by bubble floatage increase. Accordingly, the "drove efficiency" to molten steel of the lifting gas and the $G_{m}$ increase. When other parameters are fixed, the liquid level in vacuum chamber increases with the $H_{\mathrm{imm}}$. The rising distance of the bubble increases and the contact time with the molten steel is longer, and the "drove efficiency" to molten steel of lifting gas increases, so the $G_{m}$ increases.

However, $H_{\mathrm{imm}}$ should be controlled; otherwise, the gas lifting efficiency will be inefficient. The experimental results showed that the $G_{m}$ rapidly increases with the $H_{\text {imm }}$ increase when the $Q_{m}$ was small. The $H_{\text {imm }}$ influence on the $G_{m}$ gradually decreased with the $Q_{m}$ increase. Figure 9(a) shows when the $H_{\text {imm }}$ exceeded $100 \mathrm{~mm}$, especially when the $Q_{m}$ was greater than $2.3 \mathrm{Nm}^{3} \cdot \mathrm{h}^{-1}$, the $H_{\mathrm{imm}}$ increasing had little significance to $G_{m}$. With $H_{\text {imm }}$ increase, the travel of bubbles increases, $A_{\text {loss }}$ increases when the $Q_{m}$ is fixed, and $A_{\text {steel }}$ will decrease according to equation (2). The $H_{\text {imm }}$ should be $\leq 100 \mathrm{~mm}$ and $\leq 550 \mathrm{~mm}$ on-site, which will improve the production efficiency of $\mathrm{RH}$ with arched snorkels. 


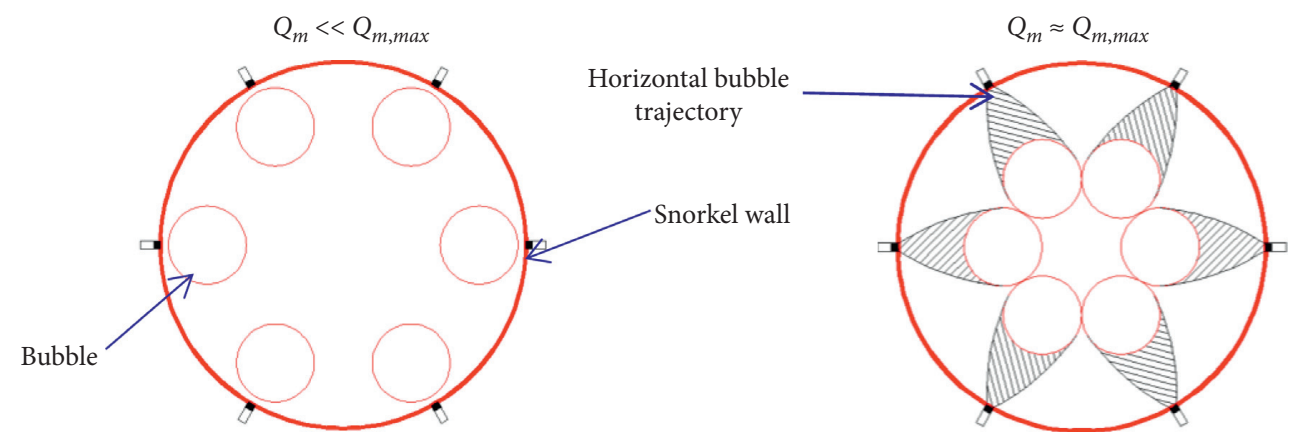

(a)
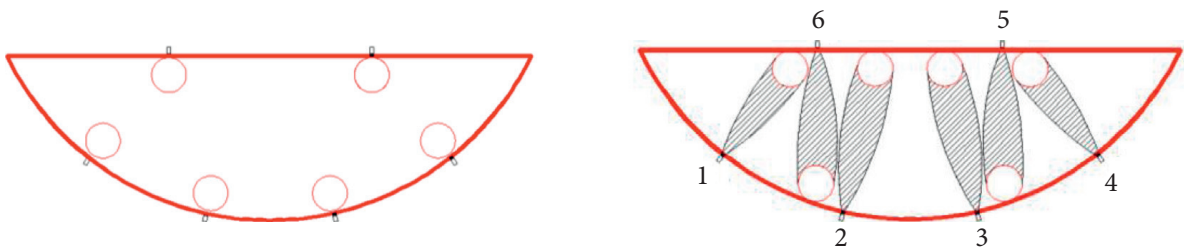

(b)

FiguRE 5: Illustration of bubble dispersion behavior in up-leg observed from the bath bottom. RH with (a) circular snorkels and (b) arched snorkels.

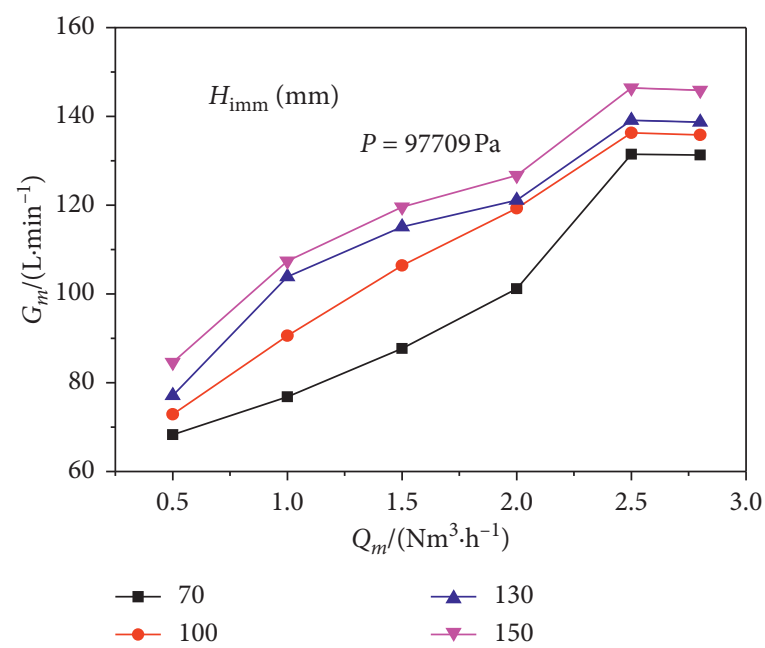

(a)

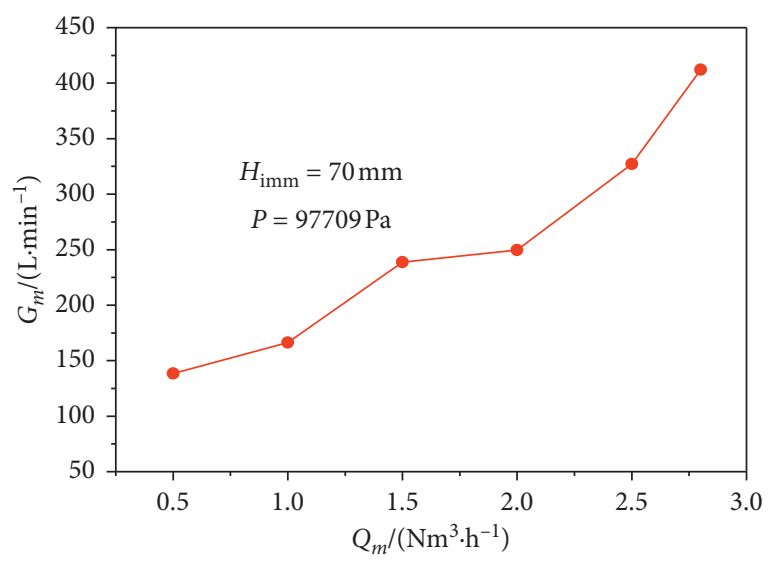

(b)

Figure 6: Variation of circulation flow rate $G_{m}$ as a function of gas flow rate $Q_{m}$. (a) RH with circular snorkels. (b) RH with arched snorkels.

The $T_{\text {mix }}$ decreased with the increase of the $Q_{m}$ and $H_{\text {imm }}$ as shown in Figure 9(b). The mixing time was obviously shortened with the increase of $Q_{m}$. The $G_{m}$ increases with the increase of the $Q_{m}$, and the downflow of molten steel into the ladle from the vacuum chamber increases, which increases the stirring of molten steel and reduces the $T_{\text {mix }}$. The $T_{\text {mix }}$ decreased with the $H_{\mathrm{imm}}$ increase at a certain vacuum degree as shown in Figure 9(b). When the $H_{\mathrm{imm}}$ was greater than $100 \mathrm{~mm}$, the trend of $T_{\text {mix }}$ decreasing was weakened. This finding indicates that the $H_{\mathrm{imm}}$ of the arched snorkels should be $\leq 550 \mathrm{~mm}$ on-site. The result of immersion depth control in the mixing time experiment is consistent with that in the circulation flow rate experiment.

Compared with then $\mathrm{RH}$ with circular snorkels, the RH with arched snorkels greatly improves the circulation flow rate, reduces the mixing time, and improves the mixing capacity. However, the refractory building is highly demanded. The RH with arched snorkels is seldom applied on-site because the complex structure of arched snorkels. The ability of the refractory building to resist molten steel erosion of RH with arched snorkels needs be studied in the future. 


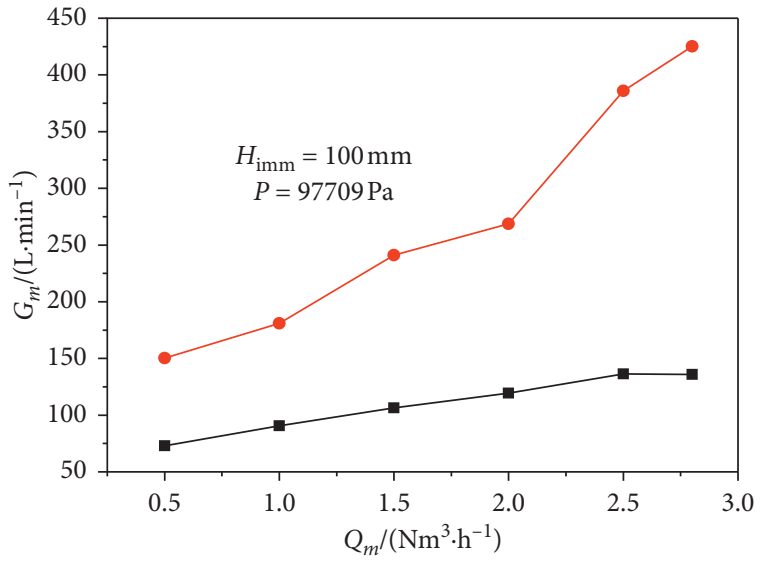

$\rightarrow$ RH with circular snorkels

$\rightarrow$ RH with arched snorkels

Figure 7: Relationship between $G_{m}$ and $Q_{m}$ in RH with arched snorkels and RH with circular snorkels.

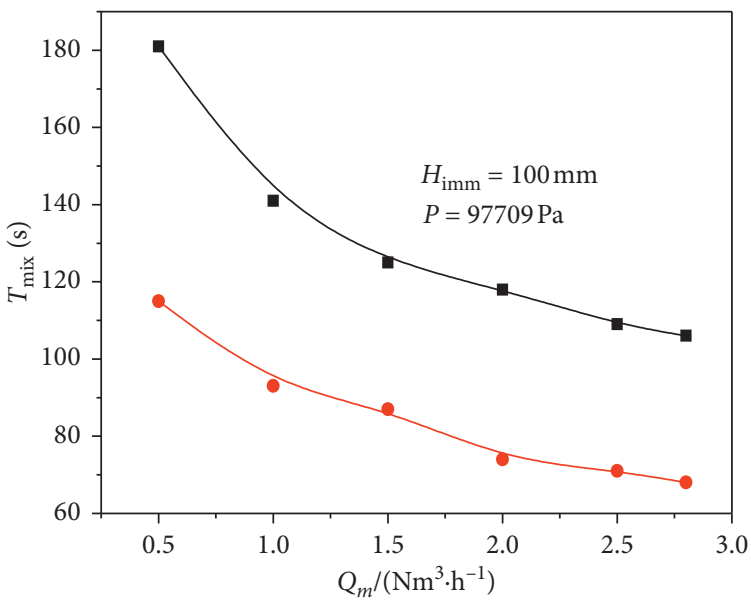

- RH with circular snorkels

$\rightarrow$ RH with arched snorkels

Figure 8: Relationship between $Q_{m}$ and $\mathrm{T}_{\text {mix }}$ in $\mathrm{RH}$ with arched snorkels and $\mathrm{RH}$ with circular snorkel.

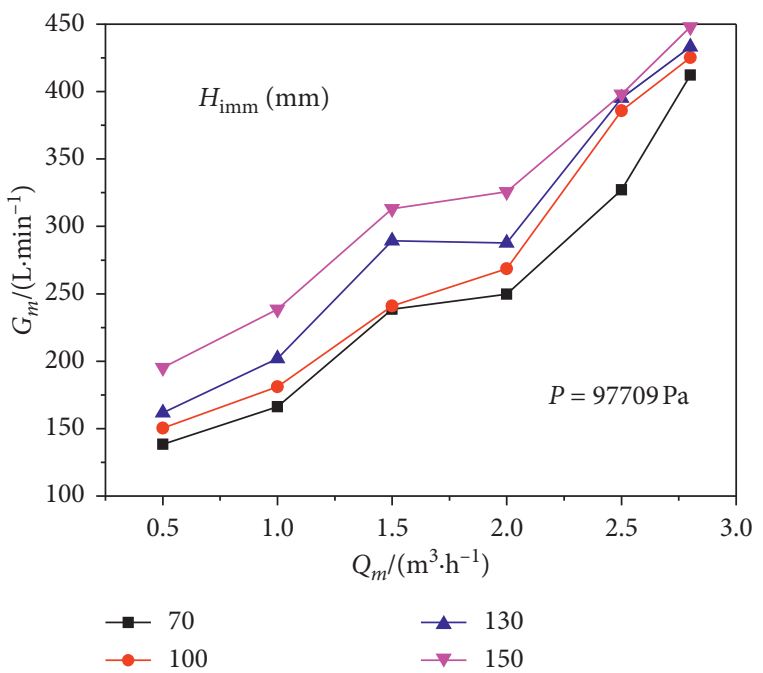

(a)

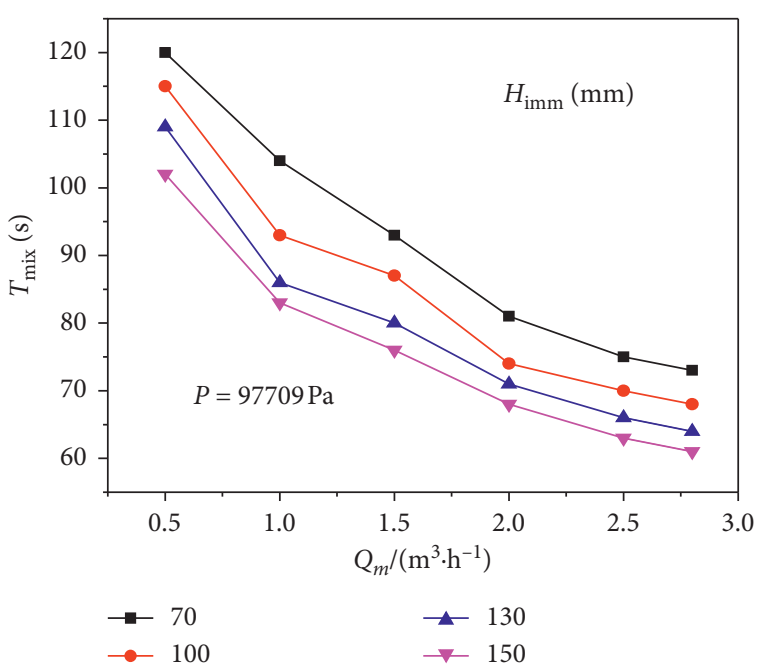

(b)

Figure 9: Effect of $Q_{m}$ and $\mathrm{H}_{\mathrm{imm}}$ on the $G_{m}$ and $\mathrm{T}_{\mathrm{mix}}$ of $\mathrm{RH}$ with arched snorkels. 


\section{Conclusions}

(1) The circulation flow rate increases 100\% 180\%, and the mixing time decreases by approximately 35\% compared with $\mathrm{RH}$ with circular snorkels in the whole range of the gas flow rate.

(2) The saturated gas flow rate of RH with arched snorkels is $99.6 \%$ more than that of RH with circular snorkels, which can greatly increase the gas flow rate range on-site.

(3) Compared with the RH with circular snorkels, the quantity of the flowing molten steel through downleg increases with the increase of the cross-sectional area and has better diffusion in the ladle while flowing to the bottom of the ladle. The RH with arched snorkels has stronger mixing capacity.

(4) The circulation flow rate increases, and the mixing time decreases with the increase of the gas flow rate and insertion depth. The insertion depth of the arched snorkel should be $\leq 550 \mathrm{~mm}$ on-site to improve the production efficiency.

\section{Data Availability}

The data used to support the findings of this study are available from the corresponding author upon request.

\section{Conflicts of Interest}

The authors declare no conflicts of interest.

\section{Acknowledgments}

The authors are grateful for support from the National Natural Science Foundation of China (Nos. U50704012, U1710257, and 51704203), Excellent Talents Science and Technology Innovation Project of Shanxi Province (No. 201605D211018), Scientific and Technological Innovation Programs of Higher Education Institutions in Shanxi (No. 2019L0656), Key Research and Development Project of Shanxi Province (No. 201903D121093), Science and Technology Innovation Project of Educational Commission of Shanxi Province (No. 2019L0616), and Doctoral Research Foundation of Taiyuan University of Science and Technology, China (No. 20142001).

\section{References}

[1] J. Pieprzyca, T. Merder, M. Saternus et al., "Physical Modelling Of The Steel Flow In RH Apparatus," Archives of Metallurgy and Materials, vol. 60, no. 3, pp. 1859-1863, 2015.

[2] M. Takahashi, H. Matsumoto, and T. Saito, "Mechanism of decarburization in RH degasser," ISIJ International, vol. 35, no. 12, pp. 1452-1458, 2007.

[3] Y. G. Park, K. W. Yi, and S. B. Ahn, "The effect of operating parameters and dimensions of the RH system on melt circulation using numerical calculations," ISIJ International, vol. 41, no. 5, pp. 403-409, 2001.

[4] Y. Luo, C. Liu, Y. Ren, and L. Zhang, "Modeling on the fluid flow and mixing phenomena in a RH steel degasser with oval down-leg snorkel," Steel Research International, vol. 89, no. 12, Article ID 1800048, 2018.

[5] D. Q. Geng, H. Lei, and J. C. He, "Numerical simulation of the multiphase flow in the rheinsahl-heraeus (RH) system," Metallurgical and Materials Transactions B, vol. 41, no. 1, pp. 234-247, 2010.

[6] L. C. Trindade, J. J. M. Peixoto, C. A. da Silva et al., "Influence of obstruction at gas-injection nozzles (number and position) in RH degasser process," Metallurgical and Materials Transactions B, vol. 50, no. 1, pp. 578-584, 2019.

[7] X. G. Ai, Y. P. Bao, W. Jiang, J. H. Liu, P. H. Li, and T. Q. Li, "Periodic flow characteristics during $\mathrm{RH}$ vacuum circulation refining," International Journal of Minerals, Metallurgy, and Materials, vol. 17, no. 1, pp. 17-21, 2010.

[8] S. K. Ajmani, S. K. Dash, S. Chandra et al., "Mixing evaluation in the RH process using mathematical modelling," Transactions of the Iron \& Steel Institute of Japan, vol. 44, no. 1, pp. 82-89, 2007.

[9] Y. Kato, H. Nakato, T. Fujii, S. Ohmiya, and S. Takatori, "Fluid flow in ladle and its effect on decarburization rate in $\mathrm{RH}$ degasser," ISIJ International, vol. 33, no. 10, pp. 1088-1094, 1993.

[10] W. Zheng, Z. P. He, G. Q. Li et al., "Physical simulation of effect of injection parameters on circulation flow rate and mixing time in $\mathrm{RH}$ vacuum refining process," Journal of Iron \& Steel Research, vol. 29, no. 5, pp. 373-381, 2017.

[11] G. Tokio, H. Katoh, M. Tetsuo et al., "Mixing of molten steel in a ladle with RH reactor by the water model experiment," Denki Seiko, vol. 50, no. 2, pp. 128-137, 1979.

[12] H. Ono-Nakazato, H. Tajiri, T. Usui et al., "Rate enhancement of the degassing reaction by the enlargement of $\mathrm{RH}$ and $\mathrm{DH}$ reactors," Tetsu-to-Hagane, vol. 89, no. 11, pp. 1113-1119, 2009.

[13] R. Tsujino, M. J. Nakashima, and I. Sawada, "Numerical analysis of molten steel flow in ladle of RH process," ISIJ International, vol. 29, no. 7, pp. 589-595, 1989.

[14] J. H. Wei, N. W. Yu, and Y. Y. Fan, "Study on flow and mixing characteristics of molten steel in $\mathrm{RH}$ and $\mathrm{RH}-\mathrm{KTB}$ refining processes," Journal of Shanghai University (English Edition), vol. 6, no. 2, pp. 167-175, 2002.

[15] T. Kuwabara, K. Umezawa, K. Mori, and H. Watanabe, "Investigation of decarburization behavior in RH-reactor and its operation improvement," Transactions of the Iron and Steel Institute of Japan, vol. 28, no. 4, pp. 305-314, 1988.

[16] B. Li and F. Tsukihashi, "Modeling of circulating flow in RH degassing vessel water model designed for two- and multi-legs operations," ISIJ International, vol. 40, no. 12, pp. 1203-1209, 2000.

[17] V. Seshadri, C. A. Silva, and I. A. Da Silva, "Physical modeling simulations of refining processes in Brazilian Steel Industry," Scandinavian Journal of Metallurgy, vol. 34, no. 6, pp. 340352, 2005.

[18] L. Lin, F. Bao, L. Q. Zhang, and H. L. Ou, "Physical model of fluid flow characteristics in RH-TOP vacuum refining process," International Journal of Minerals, Metallurgy, and Materials, vol. 19, no. 6, pp. 483-489, 2012.

[19] H. Ling, C. Guo, A. N. Conejo et al., "Effect of snorkel shape and number of nozzles on mixing phenomena in the $\mathrm{RH}$ process by physical modeling," Metallurgical Research \& Technology, vol. 114, no. 111, pp. 1-13, 2017.

[20] V. Seshadri, C. A. da Silva, I. A. da Silva, G. A. Vargas, and P. S. B. Lascosqui, "Decarburisation rates in RH-KTB degasser of CST steel plant through physical modelling study," Ironmaking \& Steelmaking, vol. 33, no. 1, pp. 34-38, 2013. 
[21] B. Zhu, D. Q. Liu, M. S XuRen, and B. Hu, "Effect of nozzle blockage on circulation flow rate in up-snorkel during the $\mathrm{RH}$ degasser process," Steel Research International, vol. 87, no. 2, pp. 136-145, 2015.

[22] K. Yang and J. Szekely, "A mathematical model of fluid flow and inclusion coalescence in the $\mathrm{RH}$ vacuum degassing system," Transactions of the Iron \& Steel Institute of Japan, vol. 23, no. 6, pp. 465-474, 2006.

[23] H. Ling, L. Zhang, and C. Liu, "Mathematical modeling on the fluid flow during RH degassing process," Metallurgical Research \& Technology, vol. 114, no. 4, pp. 510-519, 2017.

[24] J. H. Wei and H. T. Hu, "Mathematical modelling of molten steel flow in a whole degasser during RH refining process," Ironmaking \& Steelmaking, vol. 32, no. 5, pp. 427-434, 2005.

[25] B. Li and H. Huo, "Homogenous flow model for gas driven circulating flow in RH refining system," Acta Metallurgica Sinica, vol. 41, no. 1, pp. 60-66, 2005.

[26] H. Ling, L. Zhang, and C. Liu, "Effect of snorkel shape on the fluid flow during $\mathrm{RH}$ degassing process: mathematical modelling," Ironmaking \& Steelmaking, vol. 45, no. 4, pp. 1-12, 2016.

[27] H. Ling, F. Li, L. Zhang, and A. N. Conejo, "Investigation on the effect of nozzle number on the recirculation rate and mixing time in the RH process using VOF + DPM model," Metallurgical and Materials Transactions B, vol. 47, no. 3, pp. 1950-1961, 2016.

[28] M. K. Mondal, N. Maruoka, S. Kitamura, G. S. Gupta, H. Nogami, and H. Shibata, "Study of fluid flow and mixing behaviour of a vacuum degasser," Transactions of the Indian Institute of Metals, vol. 65, no. 3, pp. 321-331, 2012.

[29] L. Zhang and F. Li, "Investigation on the fluid flow and mixing phenomena in a ruhrstahl-heraeus (RH) steel degasser using physical modeling," JOM, vol. 66, no. 7, pp. 1227-1240, 2014.

[30] X. G. Ai, S. L. Li, N. Wang, and N. Lv, "Simulation of inclusions removal influenced by snorkel and blowing parameters in RH refining," Advanced Materials Research, vol. 291, no. 294, pp. 155-158, 2011.

[31] Z. You, G. Cheng, X. Wang, Z. Qin, J. Tian, and J. Zhang, "Mathematical model for decarburization of ultra-low carbon steel in single snorkel refining furnace," Metallurgical and Materials Transactions B, vol. 46, no. 1, pp. 459-472, 2015.

[32] G. Chen, S. He, Y. Li, and Q. Wang, "Modeling dynamics of agglomeration, transport, and removal of $\mathrm{Al}_{2} \mathrm{O}_{3}$ clusters in the rheinsahl-heraeus reactor based on the coupled computational fluid dynamics-population balance method model," Industrial \& Engineering Chemistry Research, vol. 55, no. 25, pp. 7030-7042, 2016.

[33] J. H. Wei and N. W. Yu, "Mathematical modelling of decarburisation and degassing during vacuum circulation refining process of molten steel: application of the model and results," Steel Research, vol. 73, no. 4, pp. 143-148, 2002.

[34] P. H. Li, Q. J. Wu, W. H. Hu et al., "Mathematical simulation of behavior of carbon and oxygen in RH decarburization," Journal of Iron and Steel Research International, vol. 22, no. S1, pp. 63-67, 2015.

[35] H. Watanabe, K. Asano, and T. Saeki, "Some chemical engineering aspects of R-H degassing process," Tetsu-to-Hagane, vol. 54, no. 13, pp. 1327-1342, 1968.

[36] V. Seshadri and S. L. Costa, "Cold model studies of R.H. degassing process," Transactions of the Iron and Steel Institute of Japan, vol. 26, no. 2, pp. 133-138, 1986.

[37] C. Kamata, S. Hayashi, and K. Ito, "Estimation of circulation flow rate in RH reactor using water model," Tetsu-to-Hagane, vol. 84, no. 7, pp. 484-489, 1998.
[38] S. Fan and B. Li, "Modeling of circulating flow in $\mathrm{RH}$ degassing vessel water model designed for two-and multi-leg operations," Acta Metallrugica Sinica, vol. 37, no. 10, pp. 1100-1106, 2001.

[39] D. Q. Geng, J. X. Zheng, K. Wang et al., "Simulation on decarburization and inclusion removal process in the ruhrstahl-heraeus ( $\mathrm{RH}$ ) process with ladle bottom blowing," Metallurgical and Materials Transactions B, vol. 46, no. 3, pp. 1484-1493, 2015.

[40] D. Q. Geng, X. Zhang, X. A. Liu et al., "Simulation on flow field and mixing phenomenon in single snorkel vacuum degasser," Steel Research International, vol. 86, no. 7, pp. 724-731, 2015.

[41] P. A. Kishan and S. K. Dash, "Prediction of circulation flow rate in the $\mathrm{RH}$ degasser using discrete phase particle modeling," ISIJ International, vol. 49, no. 4, pp. 495-504, 2009.

[42] G. Dian-Qiao, L. Hong, and H. Ji-Cheng, "Application of MHD phenomenon on secondary refining and continuous casting process," Journal of Iron and Steel Research(International), vol. 49, no. S2, pp. 941-944, 2012. 